\title{
Implementation of the German Mammography Screening Program (German MSP) and First Results for Initial Examinations, 2005-2009
}

\author{
Daniela Malek Vanessa Kääb-Sanyal \\ Kooperationsgemeinschaft Mammographie, Berlin, Germany
}

\section{Keywords \\ Breast cancer · Mammography · Screening · Implementation · Germany}

\section{Summary}

Background: The German Mammography Screening Program (German MSP) is population-based and intended for women aged 50-69 years (approximately 10.5 million). The program started in 2005 and was implemented within 5 years. This article describes the implementation, structure, and screening process, and presents the results of initial examinations for the prevalence phase. Methods: Data were collected annually from invitation centers (invitation, attendance), screening units (performance, outcomes), and cancer registries (incidence). Results: In 2009, 92\% of all annually eligible women were invited; $50 \%$ of the annually eligible population participated. The total cancer detection rate in the period of 2005-2009 was 8.1/1,000; the corresponding recall rate was $5.9 \%$. $19.6 \%$ of detected cancers were ductal carcinoma in situ; $76.7 \%$ of invasive cancers were $\leq 20$ $\mathrm{mm}$ in size, $30.2 \%$ were $\leq 10 \mathrm{~mm}$, and $75.3 \%$ were nodenegative. During the implementation period, incidence increased by 37 and $56 \%$ in the old and new federal states, respectively. Incidence rates decreased following the prevalence phase. Conclusion: The German MSP was successfully implemented. The results of the prevalence phase meet the target values of the European guidelines. Proper functioning of the program is also verified by its effects on breast cancer incidence. To draw reliable conclusions regarding the long-term effects of the program, results from the routine screening rounds have to be awaited.

(c) 2016 S. Karger GmbH, Freiburg

\section{Introduction}

History

Organized mammography screening has a long tradition in Europe, starting in the late 1980s in the Netherlands, Sweden, and the United Kingdom (UK) [1]. The effectiveness of mammography service screening was examined in randomized controlled trials in Sweden, the UK, the USA, and Canada. Meta-analyses of these trials calculated an overall relative risk reduction of about $20 \%$ among invited versus non-invited women [2,3].

In Germany, in the 1980s, mammography screening was proposed for the early detection of breast cancer. In subsequent years, opportunistic screening was widely used. In 2002, the German Federal Parliament determined to introduce an organized mammography screening program based on the European guidelines [4] to ensure population-wide access, standard quality, and the evaluation of performance and outcomes. In 2005, the first screening units started in the old federal states; since 2007, screening service was also offered in the new federal states. The last screening unit was opened at the beginning of 2009 .

\section{Legislative Structure}

Germany is composed of 16 federal states. The territory of the former German Democratic Republic constitutes the new federal states, while the former Federal Republic of Germany represents the old federal states. The healthcare system, population and cancer registries, as well as privacy and data protection authorities fall within each state's responsibility. When the screening program was introduced, the federal screening directives and state legislation had to be adapted. Unfortunately, to this day, the access to cancer registry data cannot be guaranteed for each federal state. 


\section{Screening Service}

The German MSP is population-based. Women aged 50-69 years who have their principal residence in Germany are eligible for screening (approximately 10.5 million). Invitation centers are responsible for inviting and scheduling women to participate in the program at the Federal State level.

There are currently 94 screening units regionally distributed in 375 mammography units. Within each screening unit, the screening service is provided by 1 or 2 chiefly responsible practitioners (heads of the screening units), together with a team of cooperating physicians (radiologists, gynecologists, pathologists, surgeons) and radiographers. The screening service covers the entire diagnostic chain (online supplemental figure; www.karger.com/?DOI=446359). The screening interval is 24 months.

Invitation centers and screening units use 1 of 2 exclusive screening software systems for data recording and evaluation.

\section{Quality Control}

The German MSP is subject to extensive quality control and management procedures. The facilities have to meet specific structural requirements, and the mammography equipment must undergo intensive physical-technical quality control. Physicians and radiographers have to maintain certain screening qualifications: special training, minimum numbers of cases, reading tests, and individual statistics on performance indicators. The head of the screening unit regularly evaluates performance and outcome indicators. Adherence to all requirements is ensured through regular certifications of the screening units. The outcomes of the entire program and the quality procedures are evaluated according to the European guidelines [5] and published yearly [6].

To implement and coordinate the program, the Kooperationsgemeinschaft Mammographie (mammography cooperative) was founded. The mammography cooperative consists of a central office and 5 regional reference centers. Together, they are responsible for quality control, evaluation of performance and surrogate parameters, and certifying the screening units. Reductions in mortality rates are evaluated externally by independent institutions.

The following sections describe the implementation of the German MSP from 2005 to 2009 and present the nationwide results of initial examinations. In addition, the effect of the program's implementation on breast cancer incidence among the eligible population is assessed.

\section{Materials and Methods}

Invitation and attendance data were provided by the invitation centers Coverage by invitation and participation are calculated based on the annual target population. The target population includes all women who are 50-69 years of age at the beginning of the given year; these data were obtained from the Federal Statistical Office. Women were not invited if they: were undergoing treatment or receiving aftercare for breast cancer; had a mammographic examination within the past year; declined the invitation; and/or objected to having their data transmitted from population registries.

Given that these women cannot be excluded from the target population, the calculated coverage by invitation and participation may be slightly underesti- mated. The participation rate is the proportion of women attending screening among the invited women. To evaluate invitation and participation within a given time period, the invitation date serves as the reference date for the chronologic assignment of data.

Performance and outcome data were provided by the screening units. To evaluate these measures within a certain period, the mammographic examination date serves as the reference date. Differences between the numbers of women who participated and those who were examined within a reported time period may thus occur.

Screen-detected cancers include all cases with a malignant histological finding (either from biopsy or surgery), as documented in the screening software. The detection rate refers to the number of women examined. To evaluate stage distribution, the tumor with the poorest prognosis is counted for each woman.

The national cancer registries supplied the data on breast cancer incidence in the eligible population. The incidence rate is calculated based on the registry data with at least $90 \%$ completeness of registration according to the internationally accepted threshold. Some registries achieved $90 \%$ completeness of registration during the reported period. These data were then included when calculating the incidence rate. Variations in regional incidences had a marginal impact on the overall results.

\section{Results}

\section{Implementation, Invitation, and Participation}

Within the first 2 years of screening, invitations remained low, reaching $5 \%$ of the target population - although up to $21 \%$ of mammography units were already operating (table 1). The number of invitations increased considerably in parallel with a strong expansion of screening and mammography units between 2007 and 2009. Full implementation was achieved at the beginning of 2009 with the opening of the last screening unit. Coverage by invitation reached $92 \%$ in 2009 . Thereafter, the number of mammography units and invitations increased only slightly.

Coverage by participation increased along with the increase in invitations from about $3 \%$ in the first year to $50 \%$ in 2009 . The participation rate remained constant at approximately $54 \%$ (table 1 ).

Since 2008, the percentage of subsequent screens has increased, reaching 30\% in 2009 (table 1). In 2010, the number of subsequent examinations exceeded the number of initial screens; 2010 is considered the first year of routine screening.

\section{Breast Cancer Incidence}

In the last 2 decades of the 20th century, the (age-standardized) breast cancer incidence in Germany increased [7]. In the last years prior to screening, the incidence in the eligible population remained constant, with a marked East-West disparity (fig. 1). Therefore, the incidence rates are presented separately for the old and new federal states.

In the old federal states, the gradual introduction of mammography screening, starting in 2005, resulted in a considerable increase (by 37\%) in the incidence by 2008 . Implementation in the new federal states began in 2007 and was completed within 2 years. This rapid development was associated with a sharp rise in incidence by $56 \%$ by 2009 . Throughout the course of the program, the incidence of non-invasive cancers increased by around 3-fold at its peak. 
Table 1. Implementation, invitation, and participation in the German Mammography Screening Program (German MSP)

\begin{tabular}{|c|c|c|c|c|c|c|}
\hline & \multicolumn{5}{|c|}{ Implementation phase } & \multirow{2}{*}{$\begin{array}{l}\text { Routine screening } \\
2010\end{array}$} \\
\hline & 2005 & 2006 & 2007 & 2008 & 2009 & \\
\hline Target population per year, $\mathrm{n}$ & $5,204,121$ & $5,213,959$ & $5,223,011$ & $5,235,531$ & $5,234,546$ & $5,233,114$ \\
\hline Established SU', n (\%) & $6(6.4)$ & $38(40.4)$ & $78(83.0)$ & $93(98.9)$ & $94(100)$ & $94(100)$ \\
\hline Established $\mathrm{MU}^{\mathrm{b}}, \mathrm{n}(\%)$ & $9(2.4)$ & $80(21.3)$ & $222(59.2)$ & $332(88.5)$ & $360(96.0)$ & $372(99.0)$ \\
\hline Invitations, $\mathrm{n}$ & \multicolumn{2}{|c|}{511,329} & $2,163,946$ & $4,083,872$ & $4,800,975$ & $4,888,368$ \\
\hline Coverage by invitation ${ }^{\mathrm{c}}, \%$ & \multicolumn{2}{|c|}{4.9} & 41.4 & 78.0 & 91.7 & 93.4 \\
\hline Participations, $\mathrm{n}$ & \multicolumn{2}{|c|}{292,956} & $1,158,808$ & $2,163,646$ & $2,608,406$ & $2,624,669$ \\
\hline Coverage by participation ${ }^{\mathrm{d}}, \%$ & \multicolumn{2}{|c|}{2.8} & 22.2 & 41.3 & 49.8 & 50.2 \\
\hline Participation rate $\mathrm{e}^{\mathrm{e}}, \%$ & \multicolumn{2}{|c|}{57.3} & 53.6 & 53.0 & 54.3 & 53.7 \\
\hline Initial examinations ${ }^{\mathrm{f}}, \%$ & \multicolumn{2}{|c|}{100.0} & $100.0^{\mathrm{g}}$ & 86.9 & 70.0 & 44.9 \\
\hline
\end{tabular}

For the period of 2005-2006, the annual data on invitation and participation are not available.

aPercentage of screening units (SU) running (total $n=94$ ).

bercentage of mammography units (MU) running (total $n=375$ ).

'Percentage of annually eligible women invited (initial and subsequent).

dPercentage of annually eligible women attending screening (initial and subsequent).

ePercentage of invited women attending screening (initial and subsequent).

fPercentage of all examinations.

${ }^{\mathrm{g}}$ Subsequent examinations for 2007 not differentiable, calculative maximum $2.3 \%$.
In 2010, the excess incidence of the prevalence phase had already dropped to about half of its maximal increase.

\section{Recall and Breast Cancer Detection in the Prevalence Phase}

From the start of the implementation period until 2009, a total of 6,017,053 women were screened, of which 4,978,696 underwent an initial examination. Table 2 shows the outcomes of those prevalent screens. Concurrently, the recall rate increased from $5.2 \%$ in $2005 / 2006$ to $6.2 \%$ in 2009 . Among initially screened women, 40,108 breast cancers (including ductal carcinoma in situ (DCIS)) were detected. The detection rate remained fairly constant at around 8 per 1,000 women. Among screen-detected cancers, DCIS accounted for $19.6 \%$, while invasive cancers were $77.4 \%$. Documentation on invasiveness was incomplete for $3 \%$ of screen-detected cancers. Data on tumor size were not available for $0.5 \%$ of invasive cancers (TX). Moreover, $76.7 \%$ of invasive cancers were $\leq 20 \mathrm{~mm}$ in size, $30.2 \%$ were $\leq 10 \mathrm{~mm}$, and $22.7 \%$ were advanced tumors measuring $>20 \mathrm{~mm}$. $75.3 \%$ of invasive cancers were lymph node-negative.

\section{Discussion}

\section{Implementation, Invitation, and Participation}

Population-based mammography screening in Germany began in 2005, which is relatively late when compared to the majority of European countries [1]. Taking into consideration the size of the target population, the federal structure, and the extent of the provided screening service, the implementation process was rapidly accomplished. Within 5 years, the German MSP had been established nationwide.

The participation rates are relatively low when compared with those of longstanding European screening countries such as Swe-

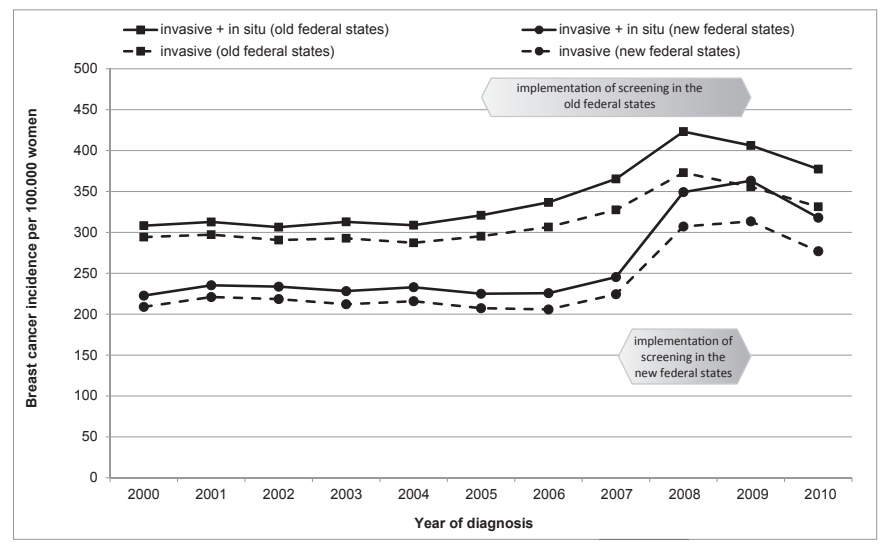

Fig. 1. Time trends in breast cancer incidence in women aged 50-69 years.

den, the Netherlands, and the UK; however, these rates are comparable with the pan-European level of 53\% [1]. This suggests that there are divergent attitudes toward mammography screening in particular, and early-detection activities in general. The reasons include the continued use of opportunistic screening and the controversial public discussion on the benefits and harms of mammography screening in Germany. In recent years, enabling an informed decision for or against participation in screening has become a primary goal of public relations and communication in Germany.

\section{Breast Cancer Incidence}

Breast cancer incidence in Germany is different in each region, with higher rates in the old and lower rates in the new federal states. The main reasons for this discrepancy are differences in medical risk factors (hormone replacement therapy, age at first child birth, birthrate per woman) and the use of early diagnosis.

The trends in incidence rates following the introduction of the MSP demonstrate effective tumor detection, and they are in line 
Table 2. Recall and detection rates for initial examinations in the implementation phase of the German Mammography Screening Program (German MSP)

\begin{tabular}{|c|c|c|c|c|c|}
\hline & 2005-2006 & $2007^{\mathrm{a}}$ & 2008 & 2009 & 2005-2009 \\
\hline Initial examinations, $\mathrm{n}$ & 293,969 & $1,088,270$ & $1,810,456$ & $1,786,001$ & $4,978,696$ \\
\hline Recalls, n (\%) & $15,362(5.2)$ & $58,108(5.3)$ & $108,050(6.0)$ & $111,010(6.2)$ & $292,530(5.9)$ \\
\hline Screen-detected cancer, $\mathrm{n} /$ per 1,000 & $2,205 / 7.9$ & $8,436 / 7.8$ & $15,033 / 8.3$ & $14,434 / 8.1$ & $40,108 / 8.1$ \\
\hline $\begin{array}{l}\text { Screen-detected cancer with data } \\
\text { on biological behavior }{ }^{\mathrm{b}}, \mathrm{n}\end{array}$ & 2,205 & 8,436 & 12,748 & 13,385 & 36,774 \\
\hline Invasive including TX, n (\%) & $1,714(77.7)$ & $6,473(76.7)$ & $9,801(76.9)$ & $10,471(78.2)$ & $28,459(77.4)$ \\
\hline Ductal carcinoma in situ, $\mathrm{n}(\%)$ & $445(20.1)$ & $1,665(19.7)$ & $2,516(19.7)$ & $2,570(19.2)$ & $7,196(19.6)$ \\
\hline Unknown, n (\%) & $46(2.1)$ & $298(3.5)$ & $431(3.4)$ & $344(2.8)$ & $1,119(3.0)$ \\
\hline $\begin{array}{l}\text { Invasive cancer including TX with } \\
\text { data on tumor size } \mathrm{e}^{\mathrm{b}, \mathrm{c}}, \mathrm{n}\end{array}$ & 1,603 & 5,551 & 9,801 & 10,471 & 27,426 \\
\hline Invasive cancers $\leq 10 \mathrm{~mm}, \mathrm{n}(\%)$ & $500(31.2)$ & $1,700(30.6)$ & $2,948(30.1)$ & $3,142(30.0)$ & $8,290(30.2)$ \\
\hline Invasive cancers $\leq 20 \mathrm{~mm}, \mathrm{n}(\%)$ & $1,240(77.4)$ & $4,293(77.3)$ & $7,533(76.9)$ & $7,974(76.2)$ & $21,040(76.7)$ \\
\hline $\begin{array}{l}\text { Invasive cancers including TX } \\
\text { with data on regional lymph node } \\
\text { involvement }^{\mathrm{b}}, \mathrm{n}\end{array}$ & 1,714 & 6,473 & 9,801 & 10,471 & 28,459 \\
\hline Invasive node-negative cancers, $\mathrm{n}(\%)$ & $1,328(77.5)$ & $4,953(76.5)$ & $7,383(75.3)$ & $7,774(74.2)$ & $21,438(75.3)$ \\
\hline
\end{tabular}

with the expectations. The initial increases in incidence of 37 and $56 \%$ correspond to observations in Sweden, Norway, and the Netherlands. They are rather high, especially given the lower participation rate $[8,9]$. This impact of screening may be attributed to the desired shift in lead time and the adverse effect of overdiagnosis.

Since 2008/2009, incidence rates declined, reflecting a transition from the detection of prevalent to incident cancers and indicating the proper functioning of the program. These trends are in accordance with the experiences reported in the UK, the Netherlands, Sweden, and Norway, though not always on a comparable scale [9-12]. Within the next few years, it can be expected that the incidence will further decrease in response to the decreasing number of first-round participants. When considering this expected decrease, the remaining rate of true overdiagnosis following appropriate program runtime and follow-up will likely be moderate and comparable to international estimates $[2,13]$.

\section{Recall and Breast Cancer Detection in the Prevalence Phase}

Of note, the recall rate rose from 5.2 to $6.2 \%$ at the end of the implementation phase, while the detection rate remained fairly constant. The course of the recall rate may have been affected by the expansion of the program, including the involvement of new physicians. It may also be credited to the first signs of a shift in the age distribution of initial screening examinations. Due to the successive start of the screening units, some units had already completed the prevalence phase by 2009 . Women that were initially invited to these units were younger on average, which would have an impact on screening outcomes. Age distribution data are not available for the presented period. The recall rates for initial examinations performed during the implementation phase in Germany comply with the European guidelines $(<7 \%)$. The rates also fall within the international range: UK (7.2\%) [14], Norway (4.6\%) [15], and the Netherlands (3.5\%) [9].
Breast cancer detection rates and tumor stage distribution also meet the expectations of a prevalence period. Both the high cancer detection rate and the stage distribution suggest the program's high level of sensitivity.

Unfortunately, the adjustment of the legal and organizational framework has not yet been completed; as such, interval cancers (and, thus, program sensitivity) cannot be evaluated nationwide. The first regional results were obtained from the cancer registries of the federal states of Lower Saxony and North Rhine-Westphalia for 2006-2008 and 2005-2008, respectively. Interval cancer rates, referred to the regional background incidence, were $23 / 27 \%$ in the first year and $56 / 54 \%$ in the second year after screening of firstround participants [16]. This yields a program sensitivity of 73 and $78 \%$, respectively, which falls within the European range of $67-$ $84 \%$ [17]. Previously published results for North Rhine-Westphalia differ slightly for the second year after screening (58\%) due to the standardization of calculation methods [18].

Based on the outcomes of initial examinations, a reliable prediction regarding the long-term effects of the screening program cannot be made; the results of routine screening rounds have to be awaited.

\section{Conclusion}

In Germany, mammography screening was promoted for early breast cancer detection in the 1980s, but not within an organized program. In 2005, an organized, quality-controlled screening program replaced opportunistic screening. The nationwide screening service was established by 2009 . The results of well-established performance parameters for the prevalence phase suggest high sensitivity and specificity of the program. The breast cancer detection rate reached the desired level with favorable tumor staging, while 
the recall rate was kept within the required limits. Reliable statements on the effectiveness of the program have yet to be made based on the results of subsequent examinations.

Although only about $50 \%$ of the eligible population were screened, the incidence rates rose by up to $50 \%$, followed by the expected drop resulting from lead time shift. Before the program was implemented, approximately 4 million mammograms were taken in Germany each year, including opportunistic screening and diagnostic mammography. In comparison, only 2.1 and 2.6 million screening examinations were carried out within the program in 2008 and 2009, respectively. Considering the widespread use of opportunistic screening, the marked effects on breast cancer incidence among the eligible population provide evidence for the proper functioning and high quality of the German MSP.

\section{Online Supplemental Material}

Online supplemental Figure Flowchart of the screening chain with responsibilities (persons and locations).

To access the supplemental figure please refer to www.karger.com/?DOI= 446359

\section{Acknowledgement}

The authors wish to acknowledge all cooperation partners at the reference centers, screening units, invitation centers, and epidemiological cancer registries for providing the data on screening examinations, participation, and breast cancer incidence.

The authors particularly acknowledge the heads of the reference centers (Dr. K. Bock, Dr. G. Hecht, Prof. Dr. W. Heindel, Prof. Dr. S. Heywang-Köbrunner, Dr. L. Regitz-Jedermann) for their advice on medical-scientific issues.

The authors also express their appreciation to Prof. Dr. A. Katalinic (Institute of Cancer Epidemiology, University of Lübeck, Germany) and Mrs. I. Urbschat (Lower Saxony Cancer Registry, Oldenburg, Germany) for their support regarding epidemiological issues.

We thank our colleague Mr. P. Rabe for providing expert advice on the documentation and evaluation specifications, as well as for technical support.

\section{Disclosure Statement}

Dr. V. Kääb-Sanyal and Dr. D. Malek are employees of the mammography cooperative. The mammography cooperative is a non-profit organization under joint partnership between the National Association of Statutory Health Insurance (SHI) Physicians and the National Association of SHI Funds. Except for employment, the authors declare that there are no conflicts of interest.

This research received no specific grants from any funding agencies in the public, commercial, or non-profit sectors.

\section{References}

1 Giordano L, von Karsa L, Tomatis M, Majek O, de Wolf C, Lancucki L, Hofvind S, Nystrom L, Segnan N, Ponti A, Van Hal G, Martens P, Danes J, von EulerChelpin M, Aasmaa A, Anttila A, Becker N, Pentek Z, Budai A, Madai S, Fitzpatrick P, Mooney T, Zappa M, Ventura L, Scharpantgen A, Seroczynski P, Morais A, Rodrigues V, Bento MJ, Gomes de Carvalho J, Natal C, Prieto M, Sanchez-Contador Escudero C, Zubizarreta Alberti R, Fernandez Llanes SB, Ascunce N, Ederra Sanza M, Sarriugarte Irigoien G, Salas Trejo D, Ibanez Cabanell J, Wiege M, Ohlsson G, Tornberg S, Korzeniewska M, Fracheboud J, Patnick JJ, Ducarroz S, Suonio E: Mammographic screening programmes in Europe: organization, coverage and participation. J Med Screen 2012;19(suppl 1):72-82.

$\checkmark 2$ Marmot MG, Altman DG, Cameron DA, Dewar JA, Thompson SG, Wilcox M: The benefits and harms of breast cancer screening: an independent review. $\mathrm{Br}$ Cancer 2013;108:2205-2240

3 Pace LE, Keating NL: A systematic assessment of benefits and risks to guide breast cancer screening decisions. JAMA 2014;311:1327-1335.

4 Perry N, Broeders M, de Wolf C, Törnberg S: European Guidelines for Quality Assurance in Mammography Screening, 3rd ed. Luxembourg, Office for Official Publications of the European Communities, 2001.

5 Perry N, Broeders M, de Wolf C, Törnberg S, Holland R, von Karsa L, Puthaar E: European Guidelines for Quality Assurance in Breast Cancer Screening and Diagnosis, 4th ed. Luxembourg, Office for Official Publications of the European Communities, 2006.
6 Evaluationsbericht 2011. Zusammenfassung der Ergebnisse des Mammographie-Screening-Programms in Deutschland. Berlin, Kooperationsgemeinschaft Mammographie, 2014

7 Krebs in Deutschland 2005/2006. Häufigkeiten und Trends. 7. Auflage. Berlin, Robert-Koch-Institut (Hrsg.) und die Gesellschaft der epidemiologischen Krebsregister in Deutschland e.V. (Hrsg.), 2010.

${ }_{8}$ Zahl PH, Strand BH, Maehlen J: Incidence of breast cancer in Norway and Sweden during introduction of nationwide screening: prospective cohort study. BMJ 2004;328:921-924.

9 Fracheboud J, de Gelder R, Otto SJ, Van Ineveld BM, Otten JD, Broeders M, Verbeek AL, den Heeten G, Holland R, de Brijn AE, de Koning H: National Evaluation of Breast Cancer Screening in the Netherlands 1990-2007. Rotterdam, National Evaluation Team for Breast cancer screening (NETB), 2009.

10 Beral V, Cush S, Ellis IO, Emery J, Faulkner K, GivenWilson R, Law M, Loughlin J, Michell MJ, Moss S, Noblet M, Patnick J, Reed M, Rubin C, Toward K, Winstone D, Austoker J, Berrington A, Blanks R, Day N, Day T, Moller H, Quinn M, Wallis MG, Wilson ARM: Screening for Breast Cancer in England: Past and Future. Sheffield, Advisory Committee on Breast Cancer Screening, 2006, NHSBSP Publication No. 61.

11 Autier P, Koechlin A, Smans M, Vatten L, Boniol M: Mammography screening and breast cancer mortality in Sweden. J Natl Cancer Inst 2012;104:1080-1093.
12 Weedon-Fekjaer H, Bakken K, Vatten LJ, Tretli S: Understanding recent trends in incidence of invasive breast cancer in Norway: age-period-cohort analysis based on registry data on mammography screening and hormone treatment use. BMJ 2012;344:e299.

13 Puliti D, Duffy SW, Miccinesi G, de Koning H, Lynge E, Zappa M, Paci E: Overdiagnosis in mammographic screening for breast cancer in Europe: a literature review. J Med Screen 2012;19(suppl 1):42-56.

14 Smith-Bindman R, Ballard-Barbash R, Miglioretti DL, Patnick J, Kerlikowske K: Comparing the performance of mammography screening in the USA and the UK. J Med Screen 2005; 12:50-54.

15 Hofvind S, Geller B, Vacek PM, Thoresen S, Skaane P: Using the European guidelines to evaluate the Norwegian Breast Cancer Screening Program. Eur J Epidemiol 2007;22:447-455.

16 Urbschat I, Heidinger O: (Determination of interval cancer rates in the German mammography screening program using population-based cancer registry data). Bundesgesundheitsblatt Gesundheitsforschung Gesundheitsschutz 2014;57:68-76.

17 Tornberg S, Kemetli L, Ascunce N, Hofvind S, Anttila A, Seradour B, Paci E, Guldenfels C, Azavedo E, Frigerio A, Rodrigues V, Ponti A: A pooled analysis of interval cancer rates in six European countries. Eur J Cancer Prev 2010;19:87-93.

18 Heidinger O, Batzler WU, Krieg V, Weigel S, Biesheuvel C, Heindel W, Hense HW: The incidence of interval cancers in the German mammography screening program: results from the population-based cancer registry in North Rhine-Westphalia. Dtsch Arztebl Int 2012;109:781-787. 